\title{
Motivators of On-job Training Among Participants of Senior Management Course Number 306 of 2019 at Kenya School of Government
}

\author{
James Muthomi Rintaugu B.Ed. (SNE), M.Ed. (SNE-EBD). \\ P.O. Box 28849-00100, Nairobi Kenya
}

\begin{abstract}
In a global perspective, motivation is the driving force within an individual for action or inaction. It has been a concern on how best to motivate employees for optimal productivity. This study established motivational factors influencing uptake of on job training courses by public servants at the Kenya School of Government (KSG) with a specific focus on the Senior Management Course (SMC) trainees' class 306/2019. It had objectives of establishing the effect of training on performance and suggesting how to maximize positive post training effects. The study employed descriptive survey design to sample all the 100 participants. Questionnaire was used for data collection. Quantitative data was tallied, frequencies obtained and presented visually while qualitative data was summarized into themes to answer research questions. This study established that majority of the participants $(36 \%)$, were motivated by promotion. However, skills development was not a top priority for the participants despite being a critical factor of performance improvement. The study recommends emphasis on skills development through differential performance identification.
\end{abstract}

Keywords: Motivators, on job training, managers, skills.

DOI: $10.7176 / \mathrm{JEP} / 10-23-12$

Publication date: August $31^{\text {st }} 2019$

\subsection{Introduction}

Motivation is concerned with why people do or refrain from doing certain things in an organization. It is a driving force within an individual which urges him/her to work towards a certain goal or reward. It stirs the willingness to work towards a goal according to Re'em (2011), in a study on motivating public sector employees, an application oriented analysis of possibilities and practical tools. Re'em (2011), further found that education plays a big role the in the socio-economic development by training skilled manpower and imparting the knowledge required for the economy. However, Re'em (2011), didn't establish motivators affecting on job training. This research established the motivational factors affecting uptake of on-the-job training by employees and their likely posttraining impact.

The general objective of this study was to establish the motivational factors influencing uptake of training courses at the Kenya School of Government (KSG), with a specific focus on the Senior Management Course (SMC) trainees.

Specific objectives of this study were to: identify the factors that influence public servants to pursue skills development courses and establish the effect of training on performance.

\section{Applicable Motivational Theories Literature}

Ball (2012), in his study on motivation theories, found out that there are several forms of theories as regards to motivation. The motivational theories relevant to this study are described subsequently. According to Maslow's Hierarchy of needs theory postulated by Abraham Maslow in 1943 and explained by Haque and Islam (2014), in a study on motivation theories, brings out the following tenets. That human need is classified into hierarchical order of five basic categories. That is, from basic psychological needs, safety, belonging and love to esteem and self-actualization. That the lowest unsatisfied need becomes the dominant or the most significant need (drives an individual to act to fulfil it). That if a need is already satisfied, it does not motivate. So, an individual progressively seeks a higher need when a lower one is fulfilled. Therefore, from Maslow's hierarchy theory, needs, action and satisfaction are closely inter-related and all lead to motivation.

Herzberg two factor theory of 1987 as explained by Dartey (2011), in a study on application of Frederick Herzberg's Two-Factor theory in Assessing and understanding employee motivation at work brings out the following. That there are some factors (motivating factors) that cause job satisfaction and motivation and some other also separated factors (hygiene factors) that cause dissatisfaction. That job satisfiers deal with the factors involved in doing the job, whereas the job dissatisfies deal with the factors which define the job context. Badubi (2017), in a study on theories of motivation and their application, established that theories of motivation are linked to serving satisfaction in employees. That motivated employees are likely to perform expected outcomes unlike the unmotivated ones. 


\section{Applicable Training Literature}

Usefulness of training programme is possible only when the trainee is able to practice the aspects learned in training programme to actual work environment (Oribabor, 2000). Elements that motivate employees and stimulate satisfaction are relevant training, appropriate placement and provision of information needed and opportunities for participation in decisions according to Sayaf (2005). However, Sayaf (2005), in a study on measuring job satisfaction patterns in Saudi Arabia's southern regions hospitals, implications for hospital staff retention, did not indicate the level and relevancy of training to the employees. This study sought the level of training of SMC participants and its relevancy to the managers.

In a research paper by special economic zones by Abdusharipovich (2018), the following is adduced. That training of relevance skills in a particular zone leads to an opportunity for improvement. This study sought prerequisite skills to SMC for relevancy and applicability.

In a service organization, such as public sector, on job training programs should be used to enhance employee's skills and to bring out the best in them and maintain a sound interpersonal relationship Kumar (2002). This helps to increase employee's involvement, trust and integrity. In this study, enhanced skills as a result of SMC course were sought.

Performance is not only the work but also includes how the work process takes place according to Manik and Sidharta (2017). Job performance shows individual behaviors that contribute to achieve organizational objectives. A study on the impact of motivation, ability, role perception on employee performance and situational factor as moderating variable of public agency in Bandung, Indonesia by Manik and Sidharta (2017), found that high level of employee perception displays a high level of job performance. That organizational performance is used as a dependent variable by most organizational performance studies and efforts are made to identify variables that produce variations in performance. In this study, motivator factors for the on-job training shall be used as predictor variable for performance.

Badubi, (2017), in his study on theories of motivation and their application in organizations found the following. That job satisfaction (or the lack thereof) depended on the employee's perception (motivation) of the degree to which his/her work delivers desired outcomes. Kumar (2002), Explains that the organizational performance is greatly affected by the individual's competencies which he described as an important variable leading to job satisfaction. That if an individual is aware of his competencies and able to control what he can and can't do, he will get more satisfaction and success in his/her career. In this study, job satisfaction was inferred from participant's level of competences.

\section{Research Design}

This study employed survey research design. It was chosen since it allowed the researcher to survey the population, analyse and describe the outcome.

\section{Target Population}

The study population comprised of 100 senior employees undertaking senior management course at Kenya school of Government lower Kabete campus from the public service. The entire survey population was chosen for better inference.

\section{Sampling Techniques and Sample size Sampling techniques}

The researcher clustered the target population purposively for inclusivity in terms of the following disciplines: Law enforcers, Medical practitioners, Educationists, Legal practitioners, Scientists, Human resource and Finance practitioners'.

\section{Sample size}

From the sampling technique, ninety four participants were surveyed after excluding the researcher and his assistants. The respondents were grouped based on their area of specialization.

\section{Research Instruments}

To achieve the objectives of this study, the researcher collected data by use of a structured questionnaire. The questionnaire collected quantitative and qualitative data on the motivational factors influencing the uptake of on the job training.

\section{Data Analysis}

Quantitative data from the survey was manually tallied, their frequencies obtained and presented visually while qualitative data collected was summarized into themes to answer research questions. Statistical software for social sciences was used for calculations and in obtaining graphical representations. 


\section{Findings and Discussions}

Questionnaire return rate

The sample size for this study was ninety-four participants drawn from seven disciplines. The total number of questionnaires filled and returned was 70.34 questionnaires were not returned. The return rate was therefore $75 \%$, and is tabulated subsequently.

Table 4.1 Questionnaire return rate

\begin{tabular}{lcl}
\hline Sample size & Questionnaires filled & Percent return rate \\
\hline 94 & 70 & $75 \%$ \\
\hline
\end{tabular}

Source: researcher (2019).

Since return rate was above $70 \%$ as per table 4.1 , over $3 / 4$ of the target population of was surveyed making inference a reality.

\section{Background Information of the Research Participants}

The study sought information on professional profiles of the research participants in terms of: gender, career specialization, work experience and highest level of education. The researcher's information was tabulated consequently.

Table 4.2 Gender distribution of respondents

\begin{tabular}{lcc}
\hline Gender & Frequency & Percentage \\
\hline Male & 40 & 57.14 \\
Female & 30 & 42.86 \\
\hline Total & 70 & 100.00 \\
\hline
\end{tabular}

Source: Researcher (2019).

From table 4.2, ratio of the participants based on gender was fairly balanced with men constituting $57 \%$ of the class as compared to $43 \%$ women.

\section{Professional Distributions of Respondents}

The respondents were drawn from various professional fields represented in the public service. It means therefore that the Senior Management Course attracted trainees across the professional cadres in the public service as shown in the following figure 4.1

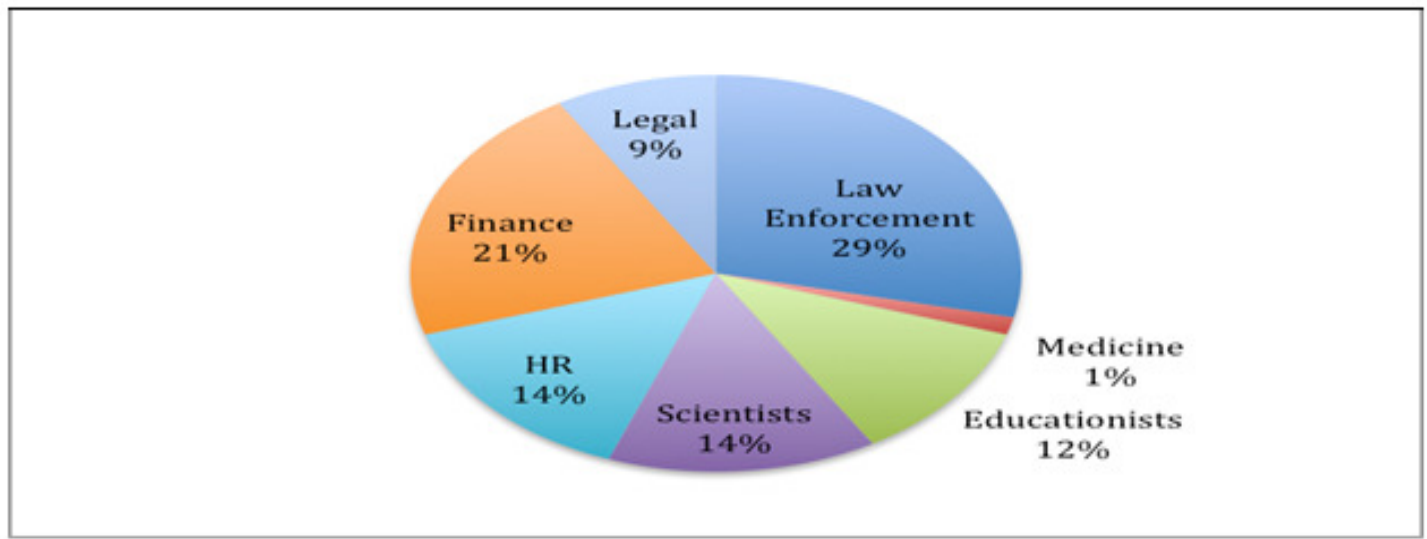

Figure 4.1 Professional distributions of respondents Source: Researcher (2019).

From figure 4.1, the SMC course attracted law enforcers most with $29 \%$ while medics were least attracted with $1 \%$.

\section{Work Experience of Respondents}

Work experience of respondents was established as shown in subsequent table 4.3.

\begin{tabular}{lrr} 
Table 4.3 Work Experience & & Percentage \\
\hline Years of Service & Frequency & 7.15 \\
\hline $0-5$ & 5 & 35.71 \\
$6-10$ & 25 & 42.86 \\
$11-15$ & 30 & 14.29 \\
Over 16 & 10 & 100.00 \\
\hline Total & 70 & \\
\hline
\end{tabular}

Source: Researcher (2019).

Majority of participants seeking capacity developments had worked between 6 and 15 years. This jelled well 
with SMC since it is a course meant for practicing managers. The minority were the newly employed at $7 \%$ which could be as a result of unidentified skill gaps and satisfaction with current position.

\section{Level of Education of Respondents}

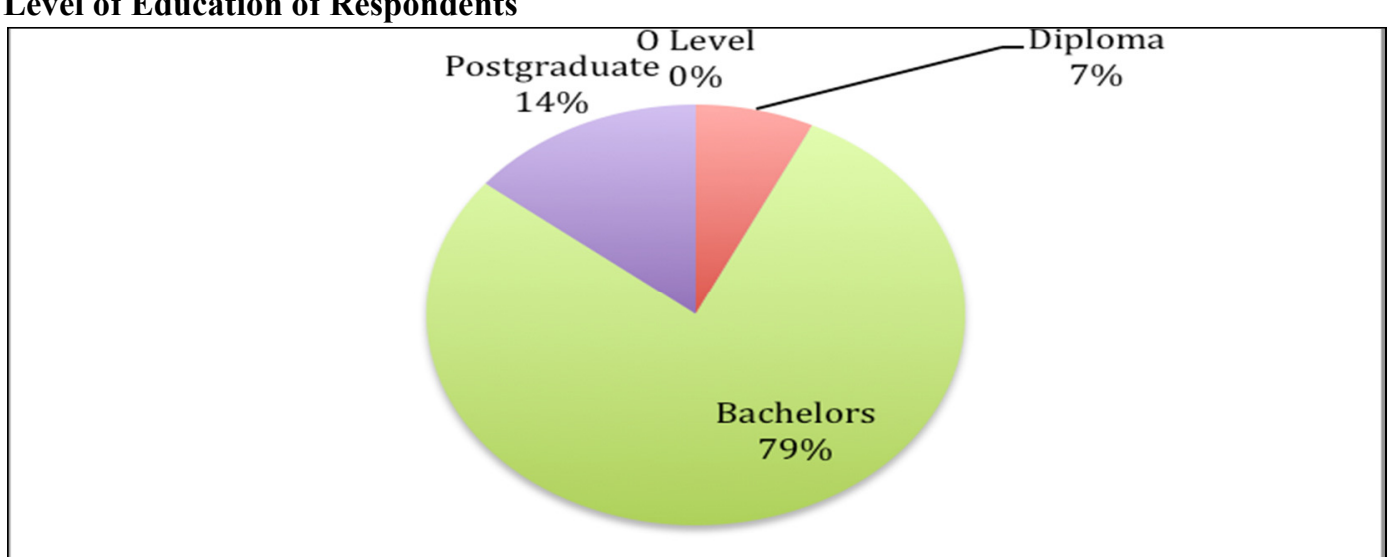

Figure: 4.2. Level of education of respondents

Source: Researcher (2019).

The highest number of SMC trainees was bachelor's degree holders with a 79\%. An observation attributed to Kenya's current educational trends.

\section{Motivators of On-job Training by Public Servants}

The study established a number of motivators on choice of on job training among public servants as illustrated subsequently.

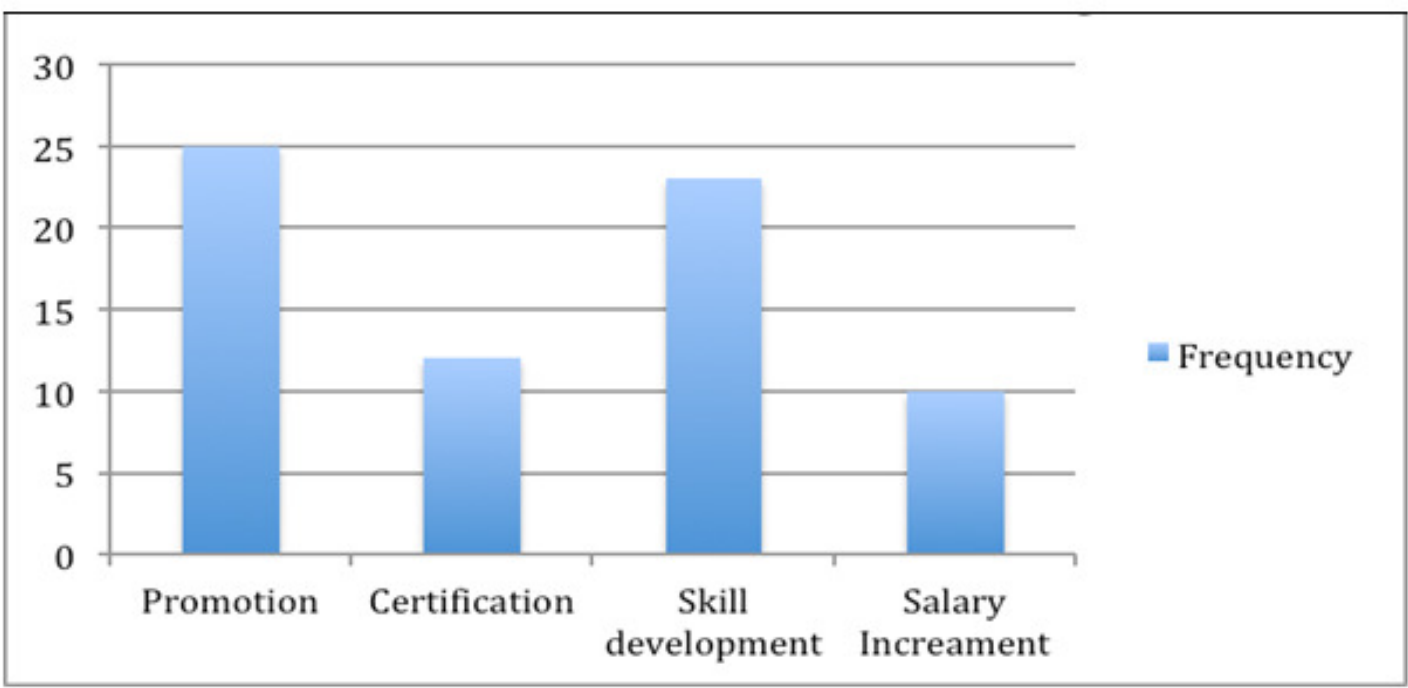

Figure 4.3 Factors influencing on-job training

Source: Researcher (2019).

From the survey, it can be deduced that majority of the respondents were motivated by promotion (36\%) in taking up the SMC training. A further significant number were driven by certification and skills search in that order. The above finding contradicts to the findings of Sayaf (2005), in that training should motivate employees. However, there is an agreement on the aspect of training stimulating satisfaction to employees.

\section{Training contribution on performance}

From the survey carried out, respondents pointed out the following as the contribution of training to their work performance. Improvement of leadership and managerial skills in areas such as interpersonal relations enhanced communication and improved etiquette. Better management of public resources, improved human Resource (HR) management, quality decision making and better conflict management were also stated as benefits that trainees acquired from the SMC class. Thus, this finding concurs with Kumar (2002) and Abdusharipovich (2018) that on job training programs enhances employee's skills. 


\section{Conclusion}

This study established that majority of the participants (36\%) in the SMC 306/2019 class, were motivated by promotion into taking up the training. This could as well be inferred to mean that participants desired the SMC certification to move higher in their grades, translating to higher salaries directly in their present jobs or through new employment opportunities. That whereas skills development is a critical factor of performance improvement in the public service from literature reviewed, it was not a top priority for the trainees'. That only 33\% cited skills development as the reason for taking SMC training.

The participants acquired managerial skills in terms of interpersonal relations, enhanced communication and improved etiquette, better management of public resources, improved HR management, better decision making and conflict management. This will contribute positively to their work performance.

\section{Recommendations}

That an emphasis on skills development should be practiced at the organization level to encourage and train participants with a desire to improve performance at their work place rather than for personal gain. This can be done by rewarding differential performers.

\section{References}

Abdusharipovich, S. (2018).Special Economic Zones as an Engine of Regional Economic Development: the best Practices and Implications for Uzbekistan. International Journal of Management Science and Business Administration. http://dx.doi.org/10.18775/ijmsba.1849-5664-5419.2014.44.1006

Badubi, R. (2017).Theories of Motivation and their Application in Organizations: A Risk Analysis. International Journal of Innovation and Development Volume 3, Issue 3, August 2017, Pages 44-51.

Ball, B. (2012). A summary of motivation theories. Retrieved from https://www.yourcoach.be/blog/wpcontent/uploads/2012/03/A-summary-of-motivation-theories 1.pdf

Dartey-Baah (2011). Application of Frederick Herzberg's Two-Factor theory in Assessing and understanding employee motivation at work: a Ghanaian Perspective.Retrieved from:https://www.researchgate.net/publication/230823567_Application_of_Frederick_Herzberg's_TwoFact or theory in assessing and understanding employee motivation at work A Ghanaian Perspective

Haque, M. \& Islam, S (2014) Motivation Theories-A critical analysis. https://www.tankonyvtar.hu/hu/tartalom/tamop412A/2011-0023_Psychology/030300.scorml

Kumar, V. (2002). Impact of Emotional Intelligence and Gender on Job Satisfaction: An Empirical Study amongst the Employees of HDFC Banks in Chandigarh Tricity, India. International Journal of Innovation and Economic Development. http://dx.doi.org/10.18775/ijied.1849-7551-7020.2015.42.2002

Manik,E \& Sidharta , I. (2017).The Impact of Motivation, Ability, Role Perception on Employee Performance and Situational Factor as Moderating Variable of Public Agency in Bandung, Indonesia. International Journal of Management Science and Business Administration. http://dx.doi.org/10.18775/ijmsba.1849-56645419.2014.34.100.

Re'em, Y. (2011). Motivating Public Sector Employees: An Application-Oriented Analysis of Possibilities and Practical Tools. Working paper No.60. July 2011.

Oribabor, P. E. (2000). Human Resources Management, A Strategic Approval, Human Resources Management 9 (4) $21-24$.

Sayaf,A. (2005). Measuring Job Satisfaction Patterns in Saudi Arabia's Southern Regions Hospitals: Implications for Hospital Staff Retention. International Journal of Management Science and Business Administration Volume 1, Issue 3, Pages 29-49 